\title{
无过渡金属参与的炔烃环化反应研究进展
}

\author{
张 䂞 $a$ 袁斯甜 ${ }^{b}$ 王 鹏*,c 刘晋彪*,d \\ ( ${ }^{a}$ 中南大学冶金与环境学院 长沙 410083 ) \\ ( $b$ 南昌海关技术中心 南昌 330002) \\ ( ${ }^{c}$ 嘉兴学院生物与化学工程学院 浙江嘉兴 314001) \\ ( $d$ 江西理工大学冶金与化学工程学院 江西赣州 341000)
}

\begin{abstract}
摘要 利用炔烃的选择性环化反应来构建碳(杂) 环化合物已经取得了令人瞩目的研究成果. 如何实现此类环化反应的 高选择性是极其重要的, 而邻位基团参与的炔烃选择性环化是非常有效的策略. 基于邻位基团参与的无过渡金属催化 体系下，就不同的邻位基团参与的炔烃环化反应研究进展进行简要综述.
\end{abstract}

关键词 炔烃; 邻位基团; 无过渡金属; 环化反应

\section{Recent Advances in Cyclization Reaction of Alkynes under Transition Metal-Free Conditions}

\author{
Zhang, Lei ${ }^{a} \quad$ Yuan, Sitian ${ }^{b} \quad$ Wang, Peng ${ }^{*, c} \quad$ Liu, Jinbiao ${ }^{*, d}$ \\ ( ${ }^{a}$ School of Metallurgy and Environment, Central South University, Changsha 410083) \\ ( ${ }^{b}$ Technology Center of Nanchang Customs, Nanchang 330002) \\ ( ${ }^{c}$ College of Biological, Chemical Science and Engineering, Jiaxing University, Jiaxing, Zhejiang 314001) \\ $\left({ }^{d}\right.$ School of Metallurgical and Chemical Engineering, Jiangxi University of \\ Science and Technology, Ganzhou, Jiangxi 341000)
}

\begin{abstract}
Remarkable achievements have been made in the construction of carbocyclic (heterocyclic) compounds through cyclization reaction of alkynes. It is vitally important to achieve the high selectivity of cyclization reactions, and neighboring group-participated selective cyclization reaction of alkynes is widely considered as an effective strategy. In this review, the recent advances in neighboring group-participated cyclization reaction of alkynes under transition metal-free conditions are summarized.
\end{abstract}

Keywords alkynes; neighboring group; transition metal-free; cyclization reaction

炔烃是一类非常重要的有机合成子, 常用于合成具 有生物活性的杂环化合物骨架 ${ }^{[1]}$. 炔烃的环化反应是构 建碳 (杂) 环化合物重要方法之一，已受合成化学家们 广泛关注 ${ }^{[2]}$. 这类碳(杂)环化合物广泛存在天然产物或 药物中, 是构建具有生理活性的化合物和药物的重要组 成; 同时也是合成某些染料、功能材料的重要原料 ${ }^{[3]}$.

利用炔烃的环化来构建碳(杂)环化合物的研究大多 采用过渡金属催化, 比如钯、铂、铑和金等贵金属, 然
而贵金属的使用存在价格昂贵、金属残留等缺点 ${ }^{[4]}$. 如 何更加高效和经济地实现炔烃的选择性环化反应，是目 前研究的热点之一 ${ }^{[5]}$. 利用邻位基团参与, 实现炔烃的 高选择性环化反应是近年来发展起来的一种有效策略. 此类方法能有效避免过渡金属的使用, 并且反应底物大 都具有简单易得、条件温和、原子经济性高等优点，在 有机合成中具有重要研究意义. 本文将基于邻位基团参 与的无过渡金属催化体系下, 就不同邻位基团参与的炔

\footnotetext{
* Corresponding authors. E-mail: liujinbiao@jxust.edu.cn; 815207636@qq.com

Received December 21, 2019; revised January 24, 2020; published online February 29, 2020.

Project supported by the National Natural Science Foundation of China (Nos. 21762018, 21961014), the Hunan Provincial Innovation Foundation for Postgraduate (No. CX20190060), the Fundamental Research Funds for the Central Universities of Central South University, and the Innovation and Entrepreneurship Training Program of Jiangxi University of Science and Technology (No. 201910407015).

国家自然科学基金(Nos. 21762018, 21961014)、湖南省研究生创新(No. CX20190060)、中南大学中央高校基础研究基金及江西理工大学大学生创新创 业训练计划(No. 201910407015)资助项目.
} 
烃环化反应研究进展进行简要综述.

\section{1 邻位氮原子参与的炔烃环化反应}

\section{1 邻位氨基(胺基)参与的炔烃环化反应}

吲哚是一类非常重要的氮杂环化合物 ${ }^{[6]}$, 寻找更加 经济和简便的方法来合成此类化合物具有重要意义. 2003 年, Knochel 等 ${ }^{[7]}$ 报道了在强碱条件下, 避免过渡金 属使用, 利用邻位氨基参与, 实现炔烃分子内五元环化 反应, 合成一系列吲哚类化合物, 提供了氮杂环化合物 的简便合成方法(Eq. 1).<smiles>[R]C#Cc1cc[R]([R10])cc1N</smiles>

随后, Fiandanese 等 ${ }^{[8]}$ 报道以邻二乙炔基苯胺为底 物, 同样加入氢化钾 $(\mathrm{KH})$, 在 $N$-甲基吡咯烷酮(NMP)中 室温下反应, 邻位氨基参与二乙炔关环反应. 值得关注 的是, 远离苯胺的另一炔键得到完整保存, 并顺利得到 2-炔基吲哚类化合物(Eq. 2).

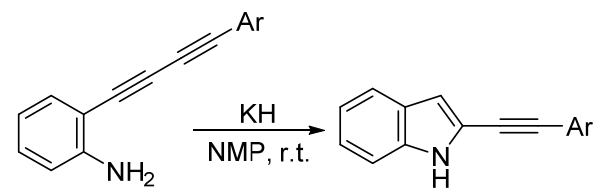

Knochel 等 ${ }^{[9]}$ 在前期研究吲哚骨架构建的基础上, 报道了一种通过区域选择性金属化合物保护的高取代 的邻炔基苯胺合成多取代吲哚的新方法. 选择性金属化 合物保护的邻炔基苯胺在 $\mathrm{TMPMgCl} \cdot \mathrm{LiCl}$ 和 $\mathrm{KH} / \mathrm{NMP}$ 条件下一锅法制备多取代吲哚化合物, 该反应过程中得 到去保护化的多取代邻炔基苯胺中间产物, 最后邻位氨 基参与炔烃的五元关环，合成高取代的吲哚化合物 (Scheme 1).
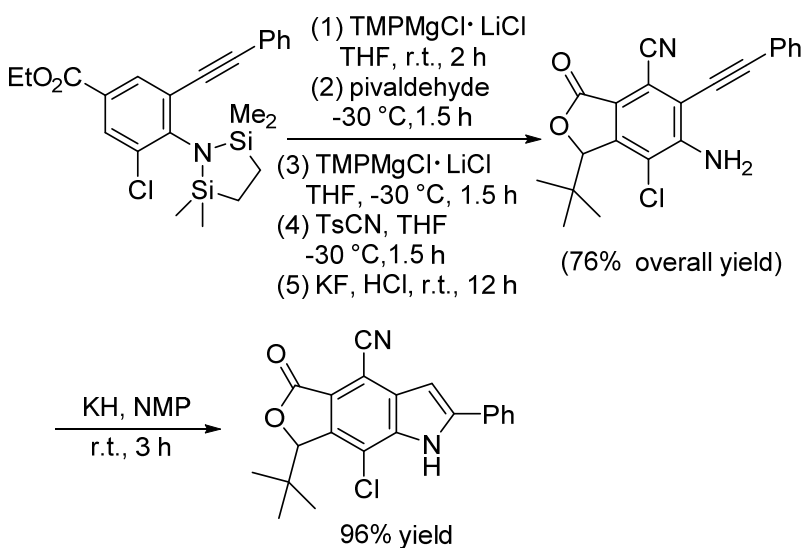

图式 1 基于邻炔基苯胺的多取代吲哚的合成

Scheme 1 Synthesis of muti-substituted indoles based on 2-alkynyl aniline
Arcadi 等 ${ }^{[10]}$ 发展了一种避免在金属催化剂或有机 酸、碱条件下合成吲哚的方法, 采用温和绿色电化学方 法. $0{ }^{\circ} \mathrm{C}$ 恒电流控制在 $25 \mathrm{~mA} \cdot \mathrm{cm}^{-2}$ 下, 在电解质体系为 $\mathrm{CH}_{3} \mathrm{CN} / 0.1 \mathrm{~mol} / \mathrm{L}$ 四乙基四氟硼酸铵(TEATFB)的铂电极 中进行电解, 电解产生的 ${ }^{-} \mathrm{CH}_{2} \mathrm{CN}$ 促使邻位氨基参与炔 烃的关环，实现吲哚化合物的合成(Eq. 3). 另外文中还 提到在电解结束时再加入邻炔基苯胺, 其目的是避免底 物中敏感官能团的还原.
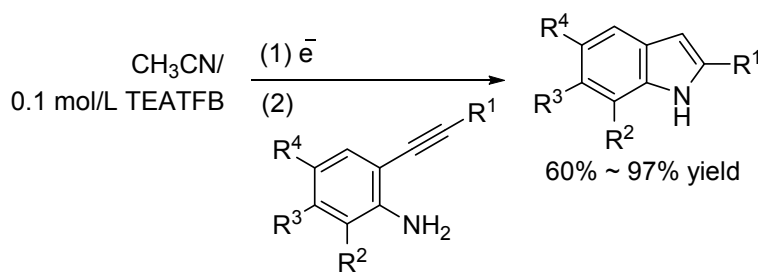

2004 年, Lorack 等 ${ }^{[11]}$ 采用碘单质代替过渡金属催化 剂, 实现炔烃的五元环化反应. 在 $\mathrm{I}_{2} / \mathrm{CH}_{2} \mathrm{Cl}_{2}$ 体系中, 以 邻位叔胺为参与基团制备 $N$-烷基-3-碘吲哚系列化合物 (Eq. 4). 当胺基上的氮连接两个不同的烷基，该反应呈 现出有趣的选择性，其中氮上带有甲基和正丁基的化合 物进行亲电环化反应, 以 $72: 28$ (质量比)生成 $N$-正丁 基-3-碘吲哚和 $N$-甲基-3-碘吲哚混合化合物.

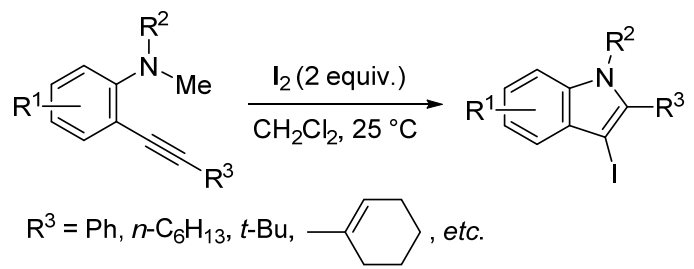

另外, 该课题组对此反应提出可能反应机理: 在亲 电试剂 $\mathrm{I}_{2}$ 作用下，活化炔烃生成碘鎓离子中间体，随后 $N, N$-二烷基胺基上的氮进攻鎓离子产生碘吲哚正离子 中间体，然后甲基以碘代甲烷的方式离去生成吲哚类化 合物(Scheme 2).

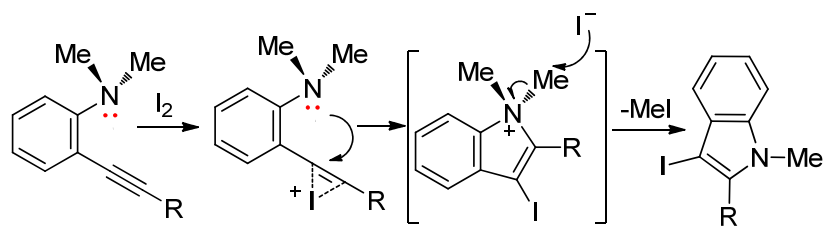

图式 $2 \mathrm{~N}, \mathrm{~N}$-二烷基邻炔基苯胺的环化反应机理

Scheme 2 Mechanism for cyclization reaction of $N, N$-dialkyl2-(1-alkynyl)anilines

Erker 等 ${ }^{[12]}$ 报道通过受阻路易斯酸碱对(FLPs)实现 了无金属催化下胺参与炔烃的分子内环化反应. 在 $\mathrm{B}\left(\mathrm{C}_{6} \mathrm{~F}_{5}\right)_{3}$ 路易斯酸条件下, 利用邻位胺进攻分子内炔烃 生成五元杂环硼酸铵衍生物(Eq. 5). 该发现证实了 FLPs 策略在杂环反应中应用的实用性. 


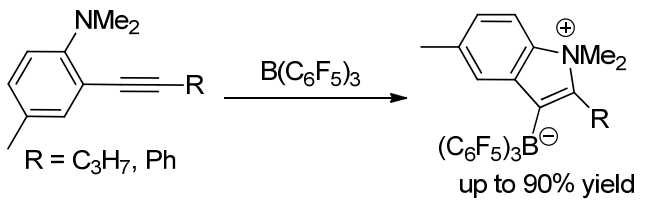

Kuhakarn 等 ${ }^{[13]}$ 发展了一种经济且环境友好的 $I_{2}-$ $\mathrm{TBHP}$ (过氧化叔丁醇)和 $\mathrm{I}_{2}$ 反应体系, 以 $N, N$-二烷基邻 炔基苯胺和磺酰肼为底物, 选择性地合成了具有潜在生 物活性的 $N$-烷基-3-磺酰基吲哚和 $N$-烷基-3-硫基吲哚类 化合物. 该反应具有良好的官能团耐受性, 产率适中至 良好(Scheme 3).

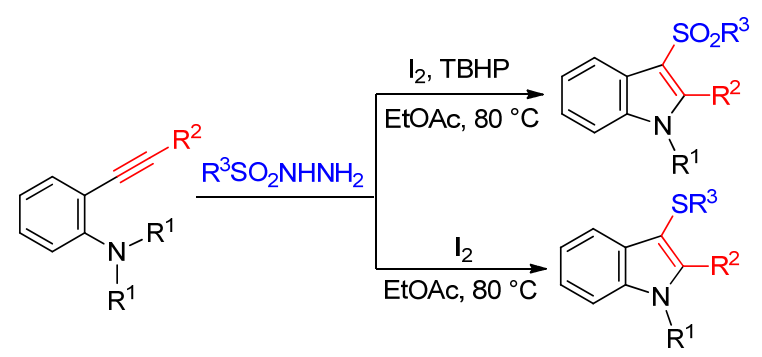

图式 3 3-磺酰基吲哚和 3-硫基吲哚的选择性合成 Scheme 3 Selective synthesis of 3-sulfonylindoles and 3-sulfanylindoles
该课题组对反应机理进行了研究, 在无碘单质或对 甲苯磺酰碘代替磺酰肼条件下，均无目标产物生成; 而 在 $\mathrm{I}_{2}$-TBHP 反应体系中加入自由基抑制剂四甲基哌啶氧 化物(TEMPO), 该反应被抑制. 根据机理研究实验和前 人研究的结果, 对在 $\mathrm{I}_{2}$-TBHP 体系下生成磺酰基吲哚的 反应提出了磺酰基自由基机理, 其可能反应机理为: TBHP 受热不稳定, 分解成叔丁氧自由基和叔丁过氧自 由基，这两个自由基与碘和磺酰肼反应生成磺酰基自由 基，同时释放 $\mathrm{N}_{2}$ ，紧接着磺酰基自由基进攻炔烃生成乙 烯基自由基中间体 $\mathbf{A}$, 随后炔烃邻位的氮原子参与氧化 环化生成吲哚中间体 $\mathbf{B}$, 最后在碘离子作用下脱烷基, 最终生成 3-磺酰基吲哚化合物. 对 $\mathrm{I}_{2}$ 反应体系生成的硫 基吲哚提出了 $\mathrm{R}^{3} \mathrm{SI}$ 对炔烃亲电加成环化的反应机理, 其可能机理为: 磺酰肼与碘反应生成 $R^{3} S I$, 然后 $R^{3} S I$ 进 攻炔烃发生亲电加成生成烯基正离子中间体 $\mathbf{C}$ ，随后炔 烃邻位的氮原子亲核进攻环化生成吲哚中间体 $\mathbf{D}$, 在碘 离子作用下脱烷基, 生成 3-硫基吲哚化合物(Scheme 4).

为了合成多取代吲哚类化合物，范仁华等 ${ }^{[14]}$ 发展 了无过渡金属催化下 $N$-Ts 邻炔基苯胺与对甲基苯硫酚

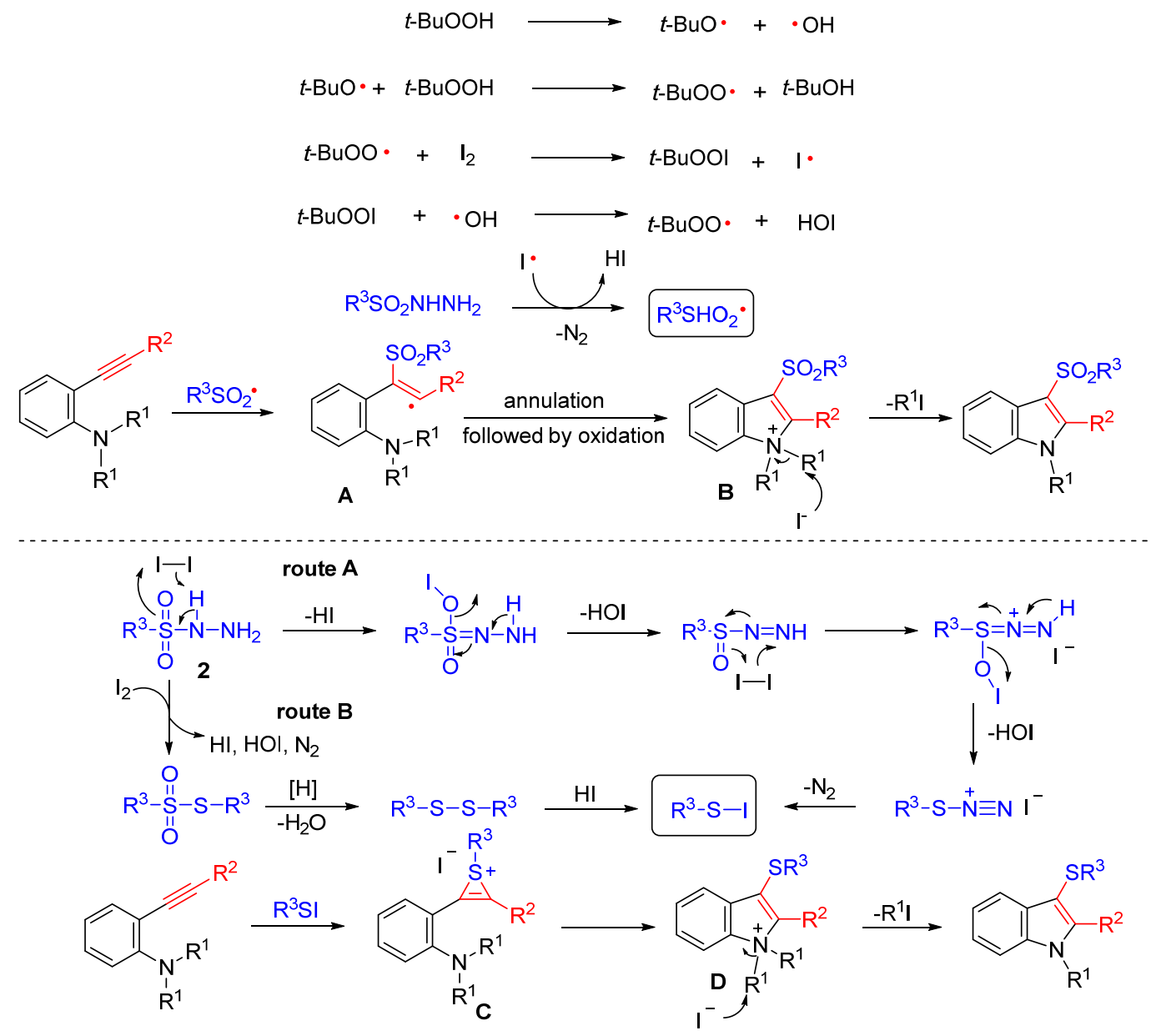

图式 $4 \quad N$-烷基-3-磺酰基吲哚和 $N$-烷基-3-硫基吲哚类化合物合成反应机理

Scheme 4 Mechanism for the synthesis of $N$-alkyl-3-sulfonylindoles and $N$-alkyl-3-sulfanylindoles 
的一锅煮反应(Eq. 6). 为研究反应的可能途径, 进行了 密度泛函理论(DFT)计算. 其机理研究表明, 该反应过 程涉及二乙酰氧基碘苯(PIDA)介导的氧化脱芳构化和 Brønsted 酸促进邻位氮原子参与的炔烃环化.

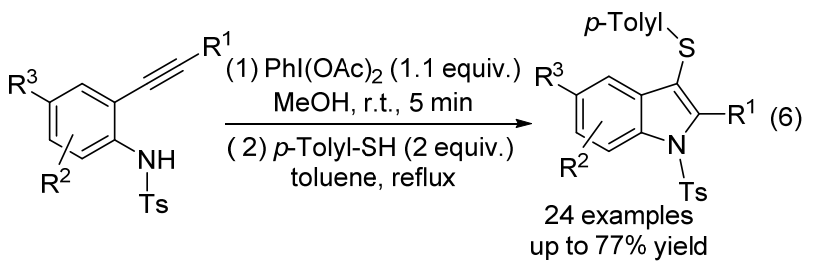

此外, 王磊等 ${ }^{[15]}$ 采用可见光诱导 2-炔基苯胺与二硫 化物 (二硒醚)的氧化环化反应, 合成了 3-硫基吲哚和 3硒基吲哚类化合物(Eq. 7). 该反应避免过渡金属和光催 化剂的使用，室温下反应，产物收率最高可达 $97 \%$.

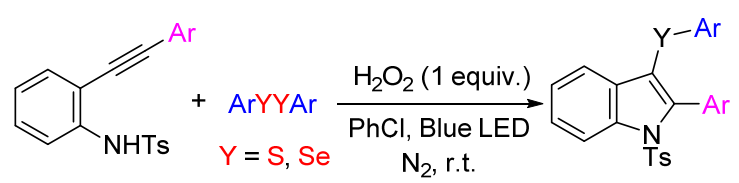

\section{2 邻位叠氮基参与的炔烃环化反应}

韩丙等 ${ }^{[16]}$ 以邻炔基芳基叠氮化合物为研究对象, 实现了邻位叠氮基参与炔烃的自由基五元环化反应. 在 叔丁基过氧化氢(TBHP)条件下, 通过 2-炔基芳基叠氮 化物与亚磺酸的反应, 开发了一种简便、有效的构建 3磺酰基吲哚化合物的方法, 该方法具有良好的选择性且 无副产物(Eq. 8). 通过自由基抑制实验，试验表明该反 应是自由基历程，提出可能反应机理为：亚磺酸在加热 条件下与 TBHP 反应生成磺酰基自由基 $\mathbf{A}$, 随后磺酰基 自由基进攻炔烃生成烯基自由基中间体 $\mathbf{B}$, 烯基自由基 立即与邻位叠氮基发生分子内环化生成吲哚 $N$-自由基 中间体 $\mathbf{C}$, 同时释放 $\mathrm{N}_{2}$, 最后中间体 $\mathbf{C}$ 从亚磺酸或周围 环境获得氢原子, 生成 3-磺酰基吲槑化合物(Scheme 5).

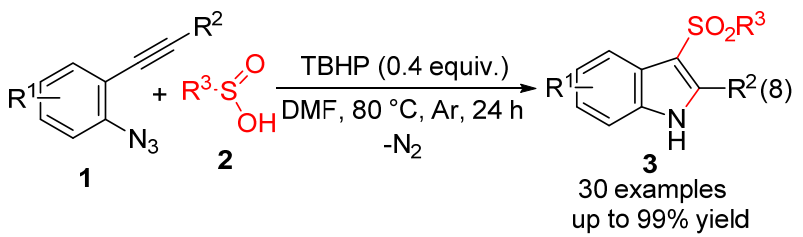

与韩丙课题组不同的是, 朱成建等 ${ }^{[17]}$ 采用 2-乙炔酮 基芳基叠氮化合物代替 2-炔基芳基叠氮化合物, 在 TBHP 条件下与芳基亚磺酸反应, 实现 2-乙炔酮基芳基 叠氮化合物的六元环化反应，同时为构建 3-磺酰基喹诺 酮化合物提供了一条高效途径(Eq. 9). 反应机理表明, 该反应也是自由基历程, 在 TBHP 下产生的磺酰基自由 基引发的六元环化反应.

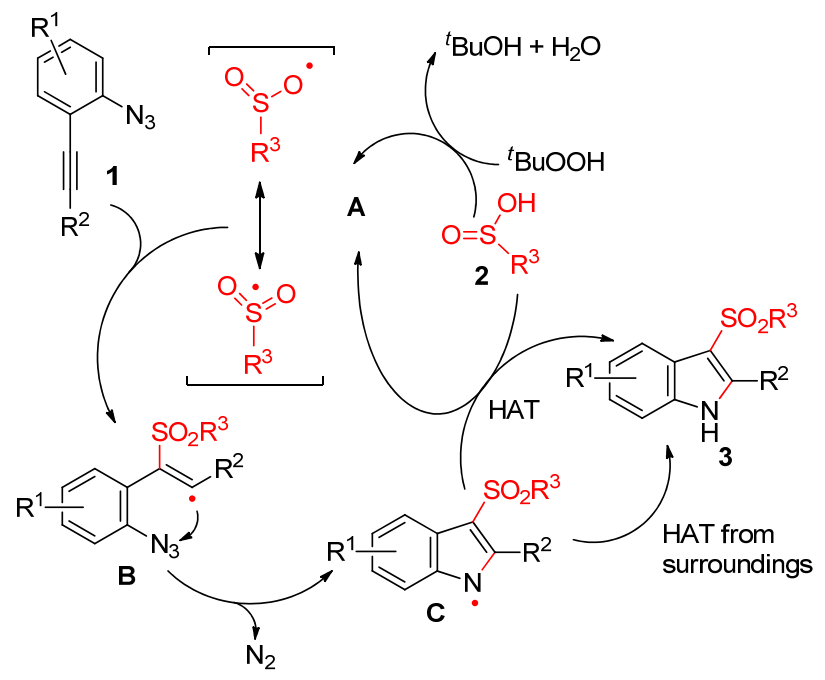

图式 52 -炔基芳基叠氮化物与亚磺酸的环化反应机理 Scheme 5 Mechanism for cyclization reaction of 2-alkynylarylazides and sulfinic acids

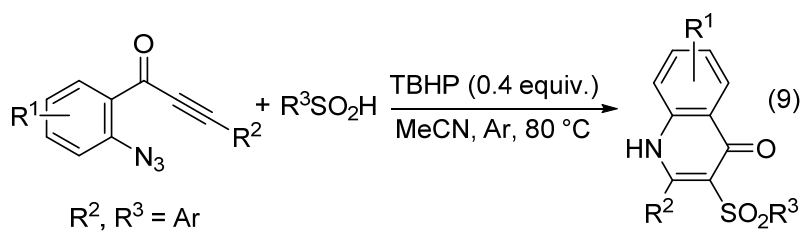

Yamamoto 等 ${ }^{[18]}$ 报道了无金属催化下邻丙炔基芳基 叠氮化合物亲电环化合成喹啉类化合物. 室温条件下, 在 $\mathrm{CH}_{3} \mathrm{NO}_{2}$ 溶剂中, 邻丙炔基芳基叠氮化合物在亲电试 剂 $\left(\mathrm{I}_{2}, \mathrm{IC} 1, \mathrm{NIS}, \mathrm{Br}_{2}, \mathrm{NBS}\right.$ 和 $\left.\mathrm{HNTf}_{2}\right)$ 作用下发生分子内六 元环化反应, 实现喹啉类化合物的合成(Eq. 10). 该反应 历程是亲电试剂进攻活化炔烃，随后邻位叠氮基参与炔 烃的关环, 最后脱去 $\mathrm{N}_{2}$ 和 $\mathrm{H}^{+}$得到喹啉类化合物.

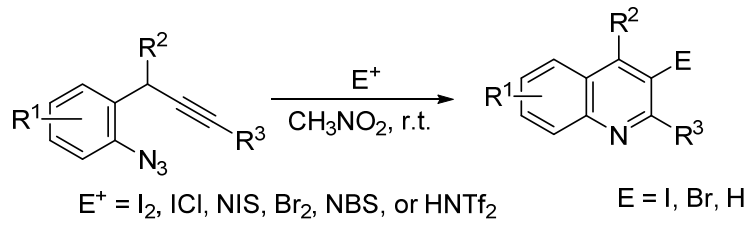

此外, Yamamoto 等 ${ }^{[19]}$ 还报道了在碘介导作用下, 2炔基芳基叠氮化合物利用邻位叠氮基参与炔烃环化反 应合成 1,3,4-三取代异喹啉化合物(Eq. 11). 根据底物结 构, 碘、Barluenga 试剂 $\left(\mathrm{Py}_{2} \mathrm{IBF}_{4} / \mathrm{HBF}_{4}\right)$ 或 $N$-碘代琥珀酰 亚胺在该反应中可被选用 $\mathrm{I}^{+}$源.

\section{3 邻位酰胺基氮参与的炔烃环化反应}

异吲哚啉-1-酮衍生物是一类重要的生物活性分子, 化学家们已陆续寻找绿色方法来合成该衍生物. Arcadi 等 ${ }^{[20]}$ 利用之前采用的电化学方法实现了 2-炔基苯胺合 成吲哚杂环化合物的方法, 发现 2-炔基苯甲酰胺在同样 
<smiles>[R]C#Cc1ccccc1C(C)N</smiles>

$R^{2}$

$\mathrm{R}^{1}=$ Aryl, Alkenyl, Alky

$\mathrm{R}^{2}=\mathrm{H}$, Alkyl, Aryl

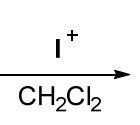<smiles>[R]c1ncc2ccccc2c1I</smiles>

$\mathrm{R}^{2}$

$55 \% \sim 95 \%$ yield
(11)

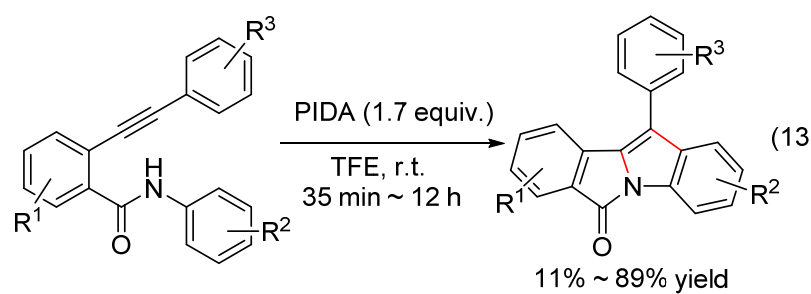

的电解质体系 $\left(\mathrm{CH}_{3} \mathrm{CN} / 0.1 \mathrm{~mol} / \mathrm{L}\right.$ TEATFB $)$ 条件下, 也能 实现五元环化反应, 有效地合成 3-乙烯基-异吲哚啉酮 类化合物(Eq. 12).

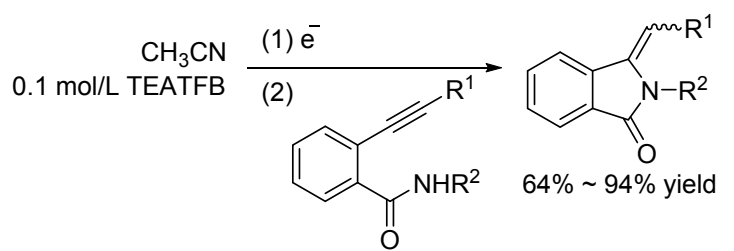

Terada 等 ${ }^{[21]}$ 发展了一种在有机超强碱作用下, 利用 有水和无水条件可以有效控制异吲哚啉-1-酮产物的 $E / Z$ 构型. 在 $10 \mathrm{~mol} \%$ 的有机超强碱 $\mathrm{P} 4-{ }^{t} \mathrm{Bu}$ 存在下, 邻炔基 苯甲酰胺在二甲基亚砜(DMSO)/ $\mathrm{H}_{2} \mathrm{O}$ 共溶剂体系中 $Z$ 选择性环化, 在无水 DMSO 溶剂中 $E$-选择性环化 (Scheme 6).

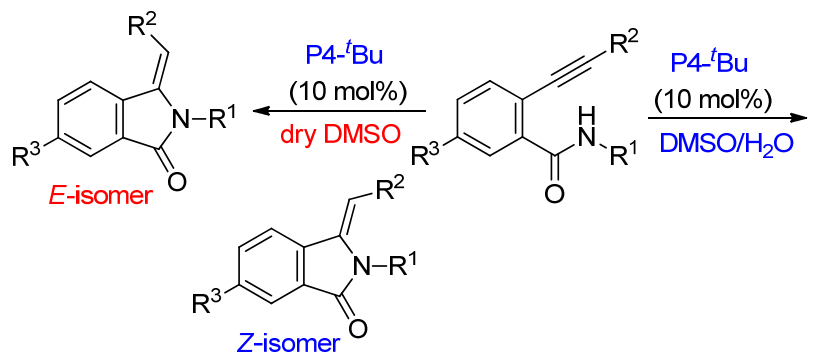

图式 6 异吲哚啉-1-酮的选择性合成

Scheme 6 Selective synthesis of isoindolin-1-ones

Maurya 等 $^{[22]}$ 开发了一种无过渡金属催化、高价碘 (III)条件下合成吲哚并异吲哚啉酮四环稠合化合物的有 效方法. 以 PIDA 为高价碘, 2-(1-芳基乙炔基)苯甲酰胺 在室温下区域选择性地合成 11-芳基- $6 H$-异吲哚[2,1- $a$ ] 吲哚-6-酮化合物, 产率中等至良好(Eq. 13). 该课题组 提出 PIDA 介导的串联氧化反应机理: 首先 PIDA 与 2-(1-芳基乙炔基)苯甲酰胺底物反应生成 $N$-碘酰胺中间 体 $\mathbf{A}$, 中间体 $\mathbf{A}$ 分解生成酰胺氮正离子中间体 $\mathbf{B}$, 随后 中间体 $\mathbf{B}$ 发生分子内氮正离子进攻炔烃环化生成碳正 离子中间体 $\mathbf{C}$, 然后发生亲电芳基取代反应生成中间体 D, 原位生成的乙酸阴离子夺取氢后生成目标产物 (Scheme 7).

Mehta 等 ${ }^{[23]}$ 报道了在 $n-\mathrm{BuLi}-\mathrm{I}_{2} / \mathrm{ICl}$ 条件下, 邻炔基 苯甲酰胺中的酰胺氮参与炔烃的碘代 $N$-环化反应，区

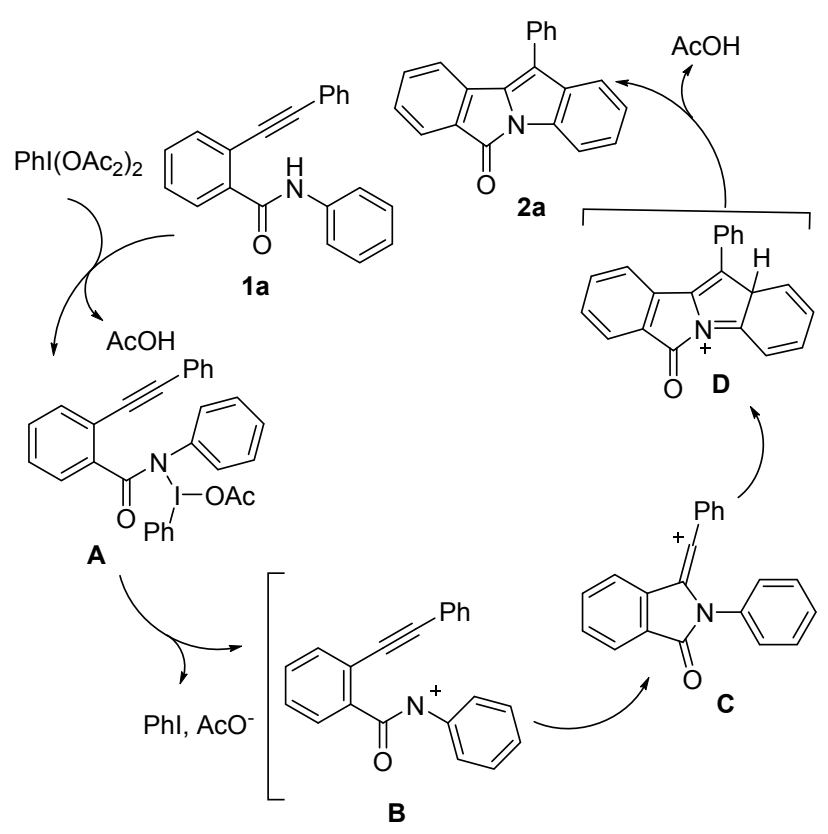

图式 7 2-(1-芳基乙炔基)苯甲酰胺的环化反应机理 Scheme 7 Mechanism for cyclization reaction of 2-(1-arylethynyl)benzamides

域选择性地合成异吲哚啉-1-酮衍生物, 并且产物的碳 碳双键为 $Z$-立体化构型(Eq. 14). 底物酰胺为伯酰胺时, 也能生成异吲哚啉-1-酮化合物，产率为 $38 \%$ ～94\%。该 反应机理也为离子机理，反应过程可能涉及异吲哚啉酮 乙烯基阴离子中间体或离子对中间体产生.

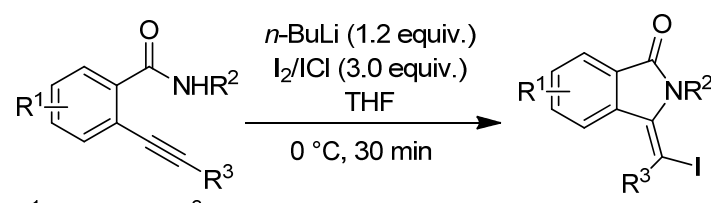

$R^{1}=\mathrm{H}, \mathrm{OMe} ; \mathrm{R}^{3}=\mathrm{H}$, alkyl, alkenyl, aryl, etc. $41 \% \sim 94 \%$ yield $\mathrm{R}^{2} \neq \mathrm{Me}, \mathrm{Ph}$

另外陈知远等 ${ }^{[24]}$ 报道了碱促进区域选择性和立体 选择性地合成( $Z$ )-3-亚烷基异吲哚啉-1-酮衍生物. 前面 $\operatorname{Terada}^{[21]}$ 和 Mehta ${ }^{[23]}$ 课题组分别采用在超强碱 P4- ${ }^{t} \mathrm{Bu}$ 和 强极性碱 $n$ - BuLi 来促进邻炔基苯甲酰胺的环异构化反 应, 而陈知远等采用碱盐 $\mathrm{Na}_{2} \mathrm{CO}_{3}$ 和超过化学计量的水 实现邻炔基苯甲酰胺中的酰胺氮参与炔烃的 $N$-环化反 应. 该反应中过量的水是必要的，对反应的转化有促进 作用，且反应绿色温和，产率适中至良好(Eq. 15). 


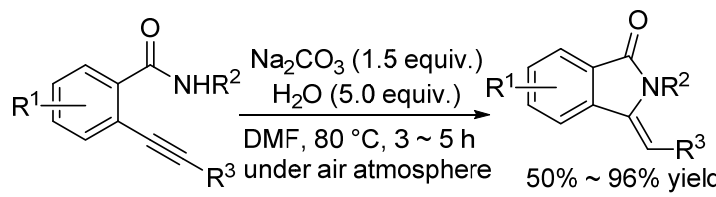

\section{2 邻位氧原子参与的炔烃环化反应}

\section{1 邻位羟基(甲氧基)参与的炔烃环化反应}

为寻找利用更加温和、更加绿色化的方法合成具有 生物活性的 $O$-杂环化合物, 近年来利用邻位含氧原子 参与的炔烃分子内环化反应已引起化学家们的广泛关 注, 在构建 $O$-杂环化合物方面也取得了较大的进展. 2009 年, Larock 等 ${ }^{[25]}$ 报道了 2 -炔基芐醇在 $\mathrm{I}_{2} / \mathrm{NaHCO}_{3}$ 条 件下, 邻位羟基参与的炔烃分子内关环反应, 生成碘取 代的异色烯和二氢异苯并呋喃类化合物(Eq. 16). 该反 应的区域选择性取决于底物结构, 特别是当底物带有叔 醇结构, 更易发生五元外环化反应, 生成二氢异苯并呋 喃类化合物; 而带有伯或仲醇基的底物，更倾向于六元 内环化反应，生成异色烯类化合物.

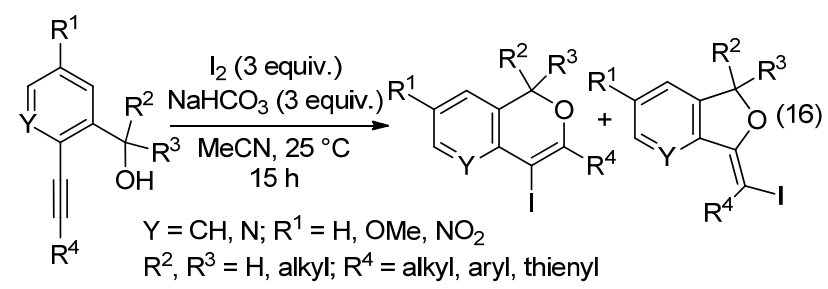

杜纪元等 ${ }^{[26]}$ 发展了一种无金属催化邻羟炔丙基苯 酚和膦氧化物的一锅煮反应. 邻羟炔丙基苯酚原位生成 $o$-QMs, 通过磷氧化物的膦-迈克尔加成以及邻位氧原 子参与关环, 有效地合成了 3-膦酰基苯并呋喃衍生物 (Eq. 17). 在 $\mathrm{C}\left(\mathrm{sp}^{2}\right)-\mathrm{P}$ 键构建的基础上, 利用光学纯的 $R_{\mathrm{P}}$-(一)-甲基苯基膦氧化物, 探讨不对称合成含有手性 $\mathrm{P}$-立体中心的 3-酰基苯并呋喃衍生物.

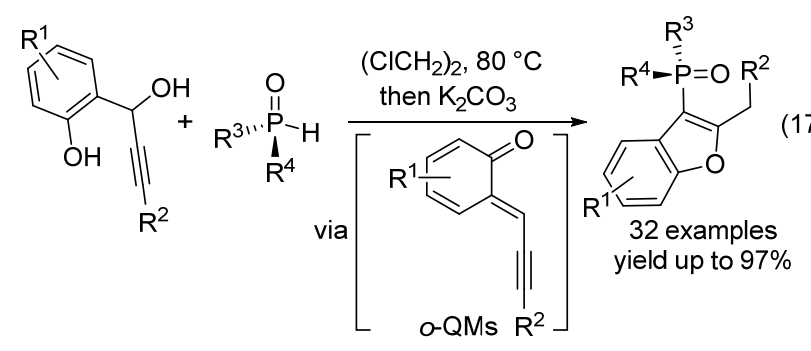

$\mathrm{Kim}$ 等 ${ }^{[27]}$ 报道了 1 -甲氧基-2-乙炔基苯在 $\mathrm{I}_{2} / \mathrm{NaHCO}_{3}$ 条件下, 利用邻位甲氧基参与炔烃关环反应, 合成碘代 苯并呋喃类化合物(Eq. 18). 其中碘代苯并呋喃产物通 过 Suzuki 偶联反应可以合成一类基于苯并呋喃骨架的 天然寡萜类化合物.

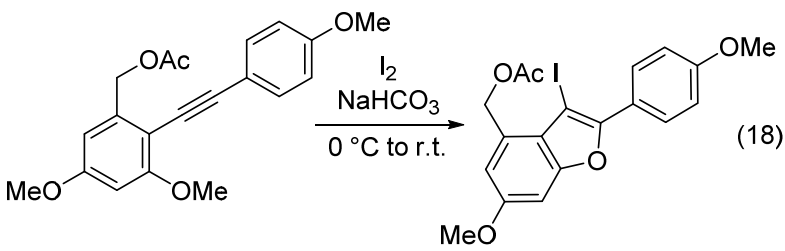

同时 Ingleson 等 ${ }^{[28]}$ 报道了在 $\mathrm{BCl}_{3}$ 催化下，利用邻位 甲氧基参与的炔烃环化反应，简便有效地合成了 $\mathrm{C} 3$-硼 化苯并呋喃衍生物. 另外二氯硼代苯并呋喃产物在频哪 醇条件下可以合成广泛存在的频哪醇硼酸酯类化合物 (Scheme 8). 在该反应体系下，炔烃邻位除了甲氧基可 以参与炔烃环化，甲硫基同样适用，可以合成 $\mathrm{C} 3$-硼化 苯并噻吩衍生物.

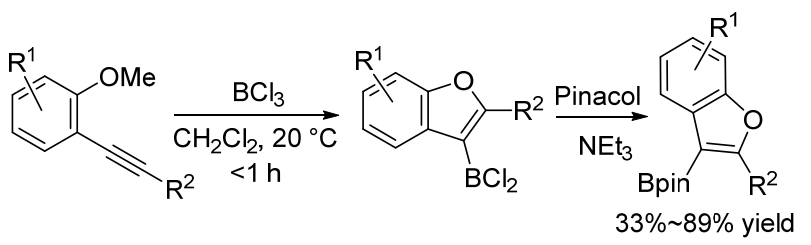

图式 8 C3-嗍化苯并噻吩的合成

Scheme 8 Synthesis of C3-borylated benzofurans

\section{2 邻位醛基(羰基)参与的炔烃环化反应}

Verma 等 ${ }^{[29]}$ 发展了在碘介导下邻炔基芳甲醛的亲 电碘代环化反应. 在 $\mathrm{I}_{2} / \mathrm{K}_{2} \mathrm{CO}_{3}$ 体系条件下, 邻炔基芳甲 醛在二氯甲烷溶剂中，与适当的亲核试剂反应，通过醛 基参与炔烃的环化反应, 形成吡喃并 [4,3- $b$ ] 喹啉衍生物 (Eq. 19). 另外，如果使用醇既作为亲核试剂又作为溶 剂，不会发生环化反应，而是氧化生成邻炔基芳基酯衍 生物.

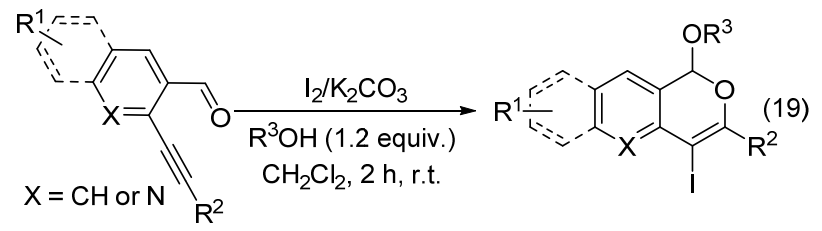

紧接着, Youn 等 ${ }^{[30]}$ 开发了一种 1,3-双(2,4,6-三甲苯 基)氯化咪唑鎓(NHC)催化邻炔基苯甲醛的分子内亲电 环化反应，区域选择性地生成苯酞和异香豆素类化合物 (Eq. 20). 该反应利用空气中氧气作为氧原子来源，将醛 氧化成相应的苯甲酸. 在 NHC 有机催化体系下, 通过 高效的双重激活，该反应以原子经济型实现两个连续 $\mathrm{C}$ - $\mathrm{O}$ 键的构建.

\section{3 邻位羧基参与的炔烃环化反应}

近些年来研究报道显示邻位羧基也能参与炔烃的 分子内环化反应. 2006 年, Uchiyama 等 ${ }^{[31]}$ 报道了 2 -炔基 苯甲酸中的邻位羧酸参与炔烃的环化反应, 有意思的是 利用酸碱条件调控分子内环化反应的区域选择性. 在强 


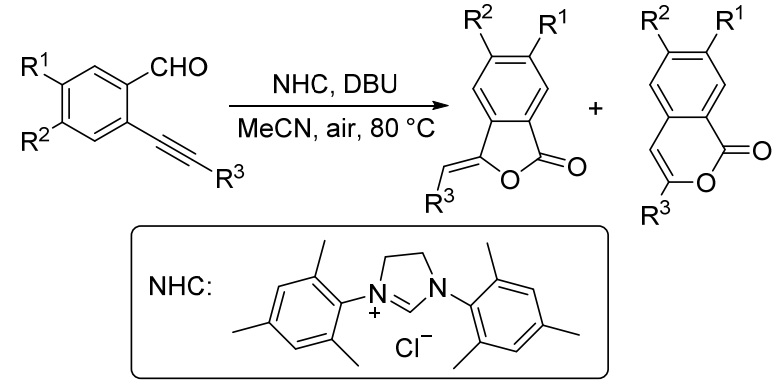

酸 $\mathrm{CF}_{3} \mathrm{SO}_{3} \mathrm{H}$ 下, 2-炔基苯甲酸区域选择性地发生六元环 化反应生成异香豆素类化合物; 而在弱碱吡啶下发生五 元环化反应生成苯酞类化合物(Scheme 9).

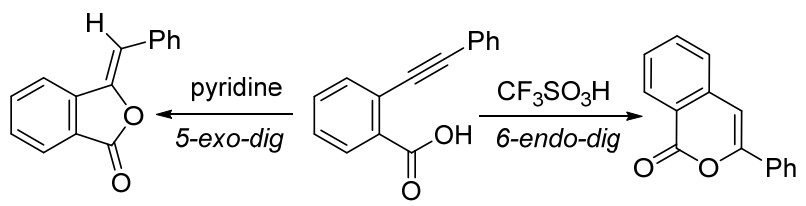

图式 9 区域调控的 2-炔基苯甲酸的分子内环化反应 Scheme 9 Regiocontrolled intramolecular cyclizations of 2-alkynylbenzoic acid

2007 年, Terada 等 ${ }^{[32]}$ 报道在有机碱 1,5 -二氮杂二环 [5.4.0]十一烯-5 (DBU)催化下, 邻炔基苯甲酸中羧基参 与炔烃的五元环化反应，区域选择性地合成了苯酞类化 合物(Eq. 21). 产率中等至良好, 为合成具有生物活性的 苯酞类化合物提供了有效方法.

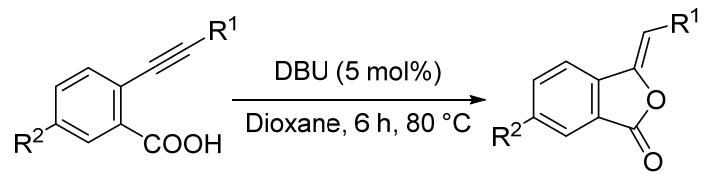

2017 年, Mancuso 等 ${ }^{[33]}$ 报道了在没有外部碱情况下, 在非常规溶剂和以分子碘为碘源的离子液体(ILs)中, 2炔基苯甲酸发生邻位羧酸参与炔烃的环化反应，该环化 反应的区域选择性强烈依赖于 ILs 介质(Scheme 10). 另 外, 从与二乙醚的反应混合物中提取产物后, ILs 溶剂可 以回收.
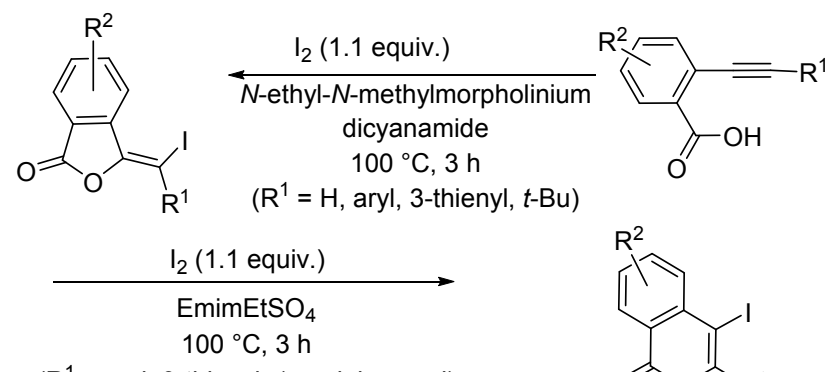

( $\mathrm{R}^{1}$ = aryl, 3-thienyl, 1-cyclohexenyl)

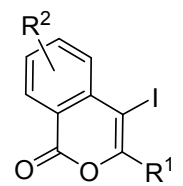

图式 10 2-炔基苯甲酸的区域选择性碘代内酯化反应 Scheme 10 Regioselective iodolactonization of 2-alkynylbenzoic acids
2018 年, 我们课题组 ${ }^{[34]}$ 以澳代四丁基铵(TBAB)为 溴盐, Oxone 为氧化剂, 在二氯乙烷和水共溶剂下实现 了邻炔基苯甲酸的五元溴环化反应，区域选择性地合成 了澳取代的苯酞类化合物(Eq. 22). 反应条件温和，且后 处理操作简便；对于产物的应用，可以通过交叉偶联反 应进行产物的衍生化，另外使其产物与水合肼在四氢呋 喃和水共溶剂下 $60{ }^{\circ} \mathrm{C}$ 反应，可以专一性地合成具有核 心结构的唒嗪-1(2H)-酮化合物.

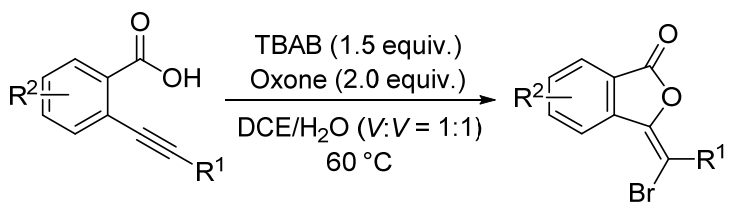

紧接着, 我们课题组发现将 1.5 equiv. TBAB 改成催 化量的 TBAB，同样以 Oxone 为氧化剂，邻炔基苯甲酸 在水溶剂下区域选择性地实现了分子内六元环化反应, 合成了异香豆素类化合物(Eq. 23).

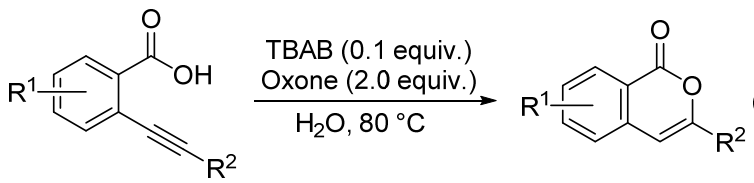

\section{4 邻位酰胺基氧参与的炔烃环化反应}

邻位酰胺基作为参与基团时，除了氮参与炔烃环化 反应, 邻位酰胺基氧也能参与炔烃的专一环化反应. 2012 年, Opatz 等 ${ }^{[35]}$ 报道了在 $\mathrm{I}_{2} / \mathrm{NaHCO}_{3}$ 条件下, 邻炔基 苯甲酰胺发生碘环化反应. 利用邻位酰胺基氧参与的炔 烃环化反应合成异苯并呋喃-1-亚胺和异色烯-1-亚胺, 取代了内酰胺的合成(Eq. 24). 并且通过 DFT 计算，反 应倾向 $\mathrm{C}-\mathrm{O}$ 键形成途径。

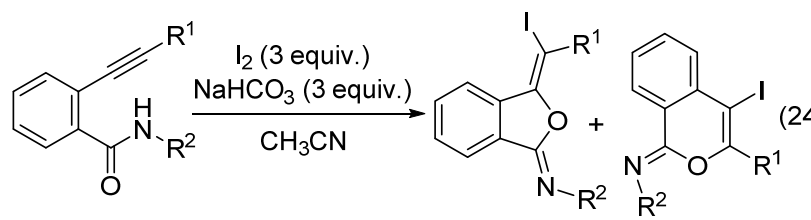

同时, Larock 等 ${ }^{[36]}$ 报道指出 2-炔基苯甲酰胺在亲电 试剂作用下环化生成异苯并呋喃-1-亚胺和异色烯-1-亚 胺类化合物, 并非是邻位酰胺氮参与的炔烃环化反应生 成多取代异喹啉-1-酮和 3-乙烯基异吲哚酮类化合物 (Eq. 25). 利用 $X$ 射线晶体学和光谱技术对产物进行了 表征，纠正该课题组先前发表产物结构的错误.

前面报道的 2-炔基苯甲酰胺在发生氧环化反应时, 同时生成五元和六元环化产物。为提高反应区域选择 性, 我们课题组 ${ }^{[37]}$ 报道了在 TBAB/Oxone 体系下, 2-炔 基苯甲酰胺在碳酸钾下能够专一选择性地发生五元溴 


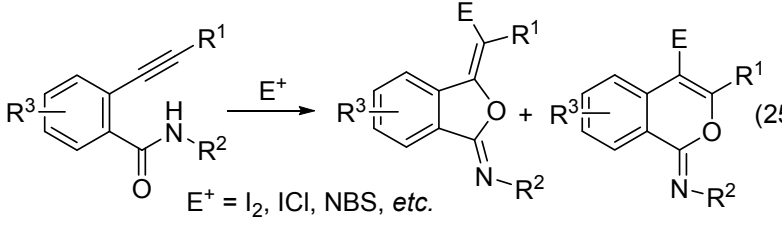

环化反应，合成异苯并呋喃-1-亚胺类化合物. 在反应完 全生成异苯并呋喃-1-亚胺化合物后, 加入酸能够完全 转化成异苯并呋喃酮类化合物(Eq. 26).

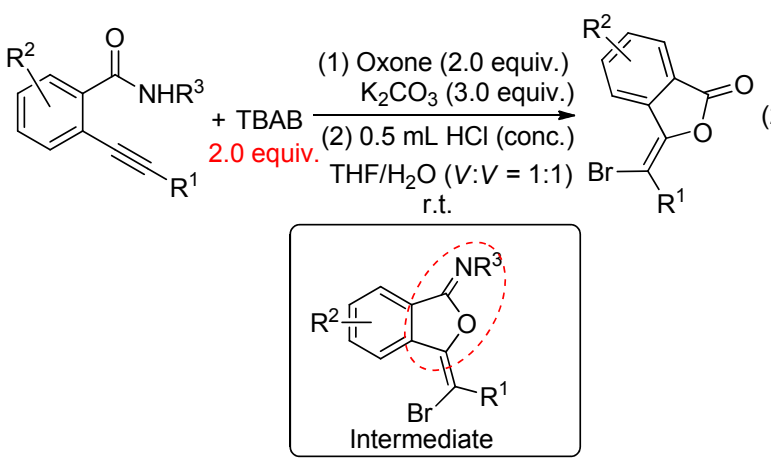

针对该反应, 我们课题组提出两种可能反应机理. 第一条反应途径可能是经过自由基溴化氧环化反应: 在 此过程中, 溴化物被氧化成溴自由基, 然后溴自由基进 攻炔烃生成烯基自由基中间体 $\mathbf{A}$, 中间体 $\mathbf{A}$ 被氧化成烯 基正离子中间体 $\mathbf{B}$, 随后被分子内酰胺氧捕获发生关环 得到异苯并呋喃-1-亚胺. 第二条反应途径可能是: 溴被 氧化成溴正离子, 然后溴正离子活化炔烃生成中间体 C, 从而促使邻位酰胺氧参与的五元亲电环化反应. 然 而根据 Larock 等 ${ }^{\left[{ }^{[3]}\right]}$ 研究, 2-炔基苯甲酰胺的亲电环化不 具有区域选择性. 若反应是通过亲电环化反应进行, 将 产生五元环化产物和六元环化产物混合物. 根据上述结 果, 该反应优先以自由基途径区域选择性地合成目标产 物(Scheme 11).

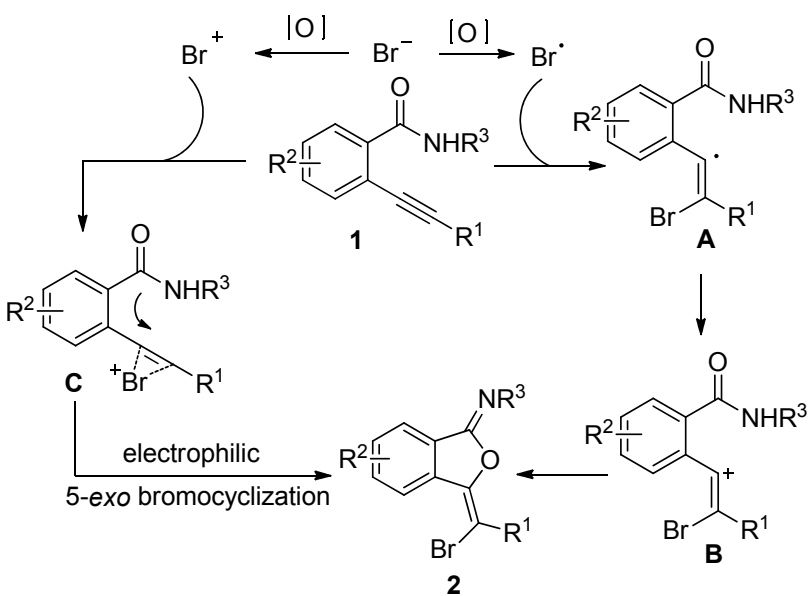

图式 112 2-炔基苯甲酰胺的环化反应机理

Scheme 11 Mechanism for cyclization reaction of 2-alkynylbenzamide
接着, 我们课题组 ${ }^{[37]}$ 发现将 $\mathrm{TBAB}$ 量降低到催化 量(0.1 equiv.)时，在 TBAB/Oxone 反应体系下, 2-炔基 苯甲酰胺发生氧环化反应，区域选择性地生成异色 烯-1-亚胺类化合物. 机理研究表明, 3-溴甲基异苯并 呋喃-1-亚胺是一个关键的中间体，经过 $\mathrm{C}-\mathrm{O}$ 键迁移 和脱澳反应生成最终的异色烯-1-亚胺类化合物(Eq. 27).<smiles>[R]NC(=O)c1cc[R]#cc1C#[R]</smiles>

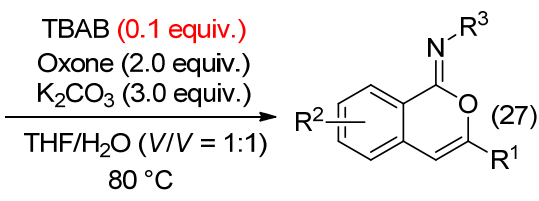

\section{3 邻位硫原子参与的炔烃环化反应}

除邻位氮、氧原子外，无过渡金属催化下邻位硫原 子也能参与炔烃的环化反应，为实现构建结构多样的杂 环化合物提供了重要途径. 2008 年, Larock 等 ${ }^{[38]}$ 报道了 在亲电试剂 $\mathrm{I}_{2}$ 下, 实现了无过渡金属催化邻位硫原子参 与的炔烃五元环化反应. 对于邻位多取代的二芳基炔 烃，炔烃邻位分别有甲硫基和甲氧基(或酯基), 能选择 性地发生硫参与的炔烃环化反应(Eq. 28).<smiles>[R]c1ccccc1C#Cc1ccccc1S(C)(=O)=O</smiles><smiles>[R]Oc1c(-c2ccccc2[R])sc2ccccc12</smiles>

2016 年, Blum 等 ${ }^{[39]}$ 首次报道无过渡金属催化下炔 烃的硫硼化反应. 以 $\mathrm{B}$-氯代邻苯二酚硼烷为( $\mathrm{ClBcat})$ 亲 电硼源，邻位甲硫基参与炔烃环化反应生成硼化苯并噻 吩类化合物(Scheme 12). 该化合物可以参与多种原位 衍生反应，在频哪醇作用下反应生成更加稳定的频哪醇 硼酸酯代苯并噻吩类化合物. 另外该课题组专门在一篇 文章通过动力学、计算等研究对反应机理进行详细论述, 提出可能反应机理为: 利用路易斯酸硼诱导活化 2-炔基 硫代苯甲醚中碳碳参键生成两性离子中间体 $\mathbf{C}$, 随后中 间体 $\mathbf{C}$ 通过氯离子脱甲基或经过离子对中间体 $\mathbf{D}$ 生成 3-硼化苯并噻吩化合物(Scheme 13). 该反应途径表明 $\mathrm{ClBcat}$ 具有关键双功能作用, 首先是作为亲电活化试 剂，其次是亲核氯化物的来源.
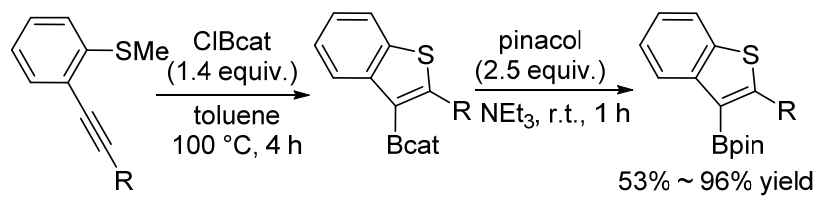

图式 12 2-炔基硫代苯甲醚的硫硼化反应

Scheme 12 Thioboration of 2-alkynylthioanisoles 

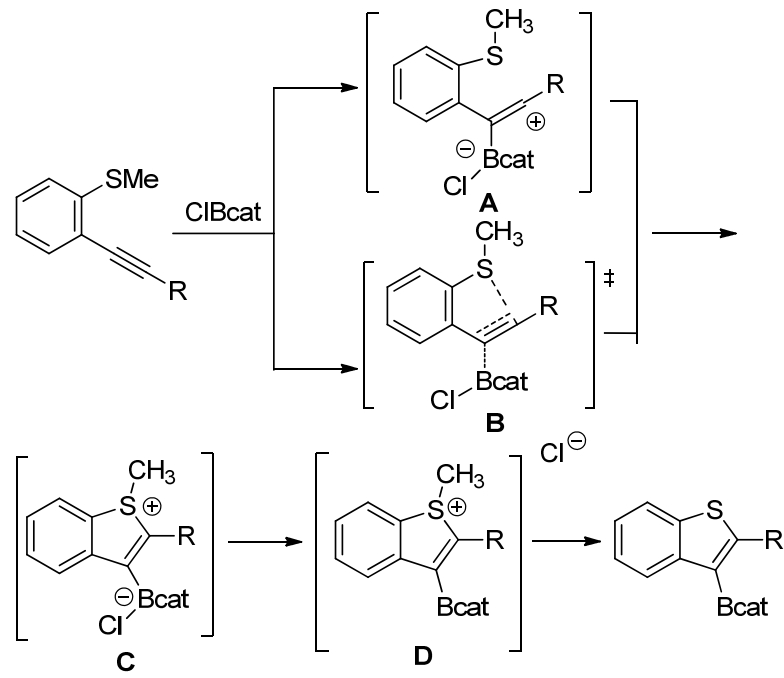

图式 13 2-炔基硫代苯甲醚的硫硼化反应机理 Scheme 13 Mechanism for thioboration reaction of 2-alkynylthioanisoles

2017 年, 宋秋玲等 ${ }^{[00]}$ 报道了 2-炔基硫代苯甲醚和 芳基亚磺酸在 TBHP 条件下甲硫基参与炔烃的自由基环 化反应，合成 3-芳基磺酰基苯并噻吩(Eq. 29). 该反应条 件温和、操作简单并且反应时间短，产率中等至良好.

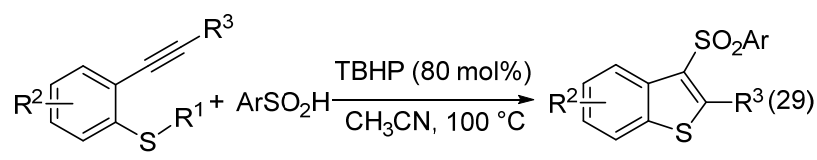

$\mathrm{R}^{1}=\mathrm{Me}, \mathrm{Et}, \mathrm{Ph}, \mathrm{Bn}$

\section{4 邻位碳原子(苯基)参与的炔烃环化反应}

利用无过渡金属催化邻位苯基参与炔烃的环化反 应，是合成稠环芳烃的一种经济有效方法. 1994 年, Swager 等 ${ }^{[41]}$ 在三氟乙酸(TFA) 条件下设计了含邻苯基乙 炔基-1,1'-联苯核心对称结构底物, 利用邻位苯基参与 炔烃的环化反应, 定向专一地合成了具有特殊结构的稠 环芳烃(Eq. 30). 另外该课题组还合成了全碳梯形共轭 聚合物或石墨带，证实了该反应的实用性.
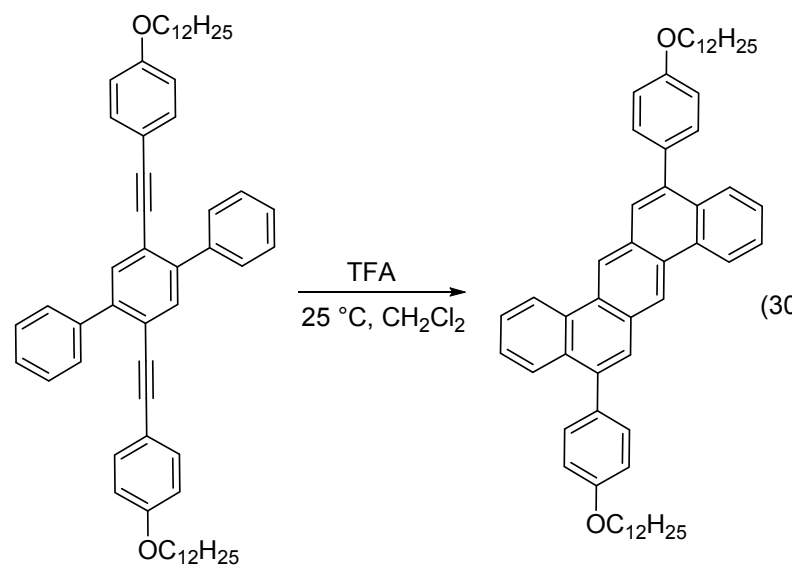

2004 年, Larock 等 ${ }^{[42]}$ 报道了在亲电试剂如 ICl 作用 下，利用 2-(芳基乙炔基)联苯的邻位苯基参与炔烃的环 化反应，合成了碘取代的稠环芳烃化合物. 芳烃取代基 可以是供电子基团或吸电子基团，具有良好的官能团耐 受性，并且该方法已经广泛应用于合成多环或杂环化合 物中(Eq. 31).

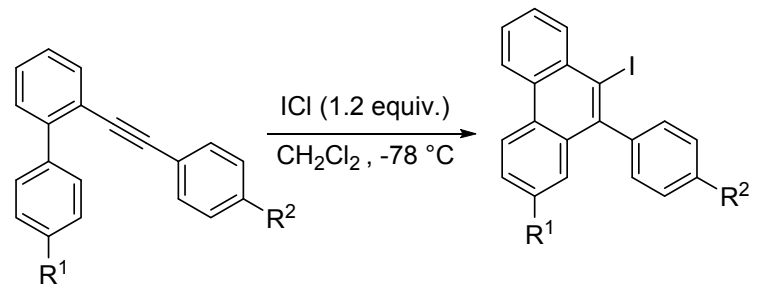

2007 年，刘瑞雄等 ${ }^{[43]}$ 也报道了在亲电试剂 ICl 作用 下，双(二芳基)炔烃发生分子内环化合成碘菲类化合物, 该产物通过 Mizoroki-Heck 偶联反应可以合成二苯并 [g,p]联苯. 另外该课题组发现以 4'-甲氧基-2-乙炔基联 苯为底物，在 $\mathrm{ICl}$ 作用下发生 ipso 环化得到双环螺环己 二烯酮. 在 $\mathrm{MeOH} / \mathrm{H}_{2} \mathrm{SO}_{4}$ 条件下，这些螺酮产物通过选 择性的 1,2-烯基转移进行重排，得到碘菲类化合物 (Scheme 14).

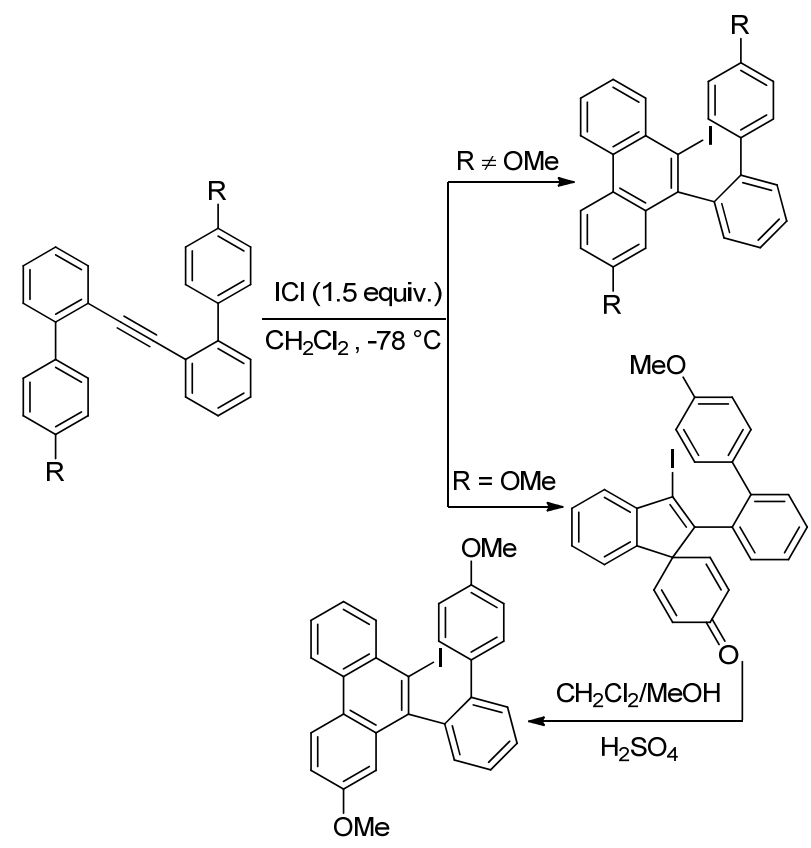

图式 $14 \mathrm{ICl}$ 促进的双二芳基乙炔的环化反应

Scheme 14 ICl-promoted cyclization of bis(biaryl)acetylenes

为实现七元环化反应, Chen 等 ${ }^{[44]}$ 设计了 1-([1,1'-联 苯]-2-基)炔酮底物代替 1-([1,1'-联苯]-2-基)炔烃化合物, 在氯化碘条件下，利用邻位苯基参与的炔烃环化反应合 成了碘代二苯并环庚-5-酮. 通过改变炔酮底物上的取 代基，可能发生分子内 6 元环化反应生成螺环共轭化合 
物(Eq. 32).

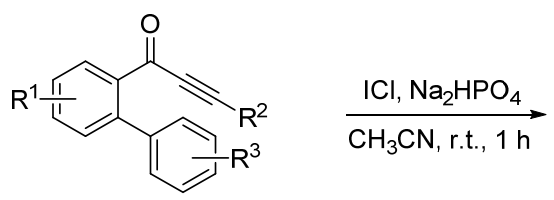<smiles></smiles><smiles>[R]C1=C(I)C(=O)c2cc[R1]([H])cc2C12C=CC(=O)C=C2</smiles>

Park 等 ${ }^{[45]}$ 设计了吲哚炔胺类底物, 邻位苯基选择性 地参与炔烃的环化反应. 在三氟甲磺酸 $(\mathrm{TfOH})$ 介导下, 通过吲哚 $\mathrm{C} 3$ 上的吸电子官能团来控制环异构化, 含羰 基的吲哚类底物(如 $\mathrm{CO}_{2} \mathrm{Et}$ 和 $\mathrm{COMe}$ )发生六元环化, 生 成吡咯并[3,2,1-ij]喹啉化合物; 而含有磺酰基的吲哚类 底物(如 $\mathrm{Ts}$ 和 $\mathrm{Ms}$ )发生七元环化, 生成苯并 $[3,4]$ 氮杂环 庚烷 $[1,2-a]$ 吲哚化合物, 产率中等至以上(Scheme 15).

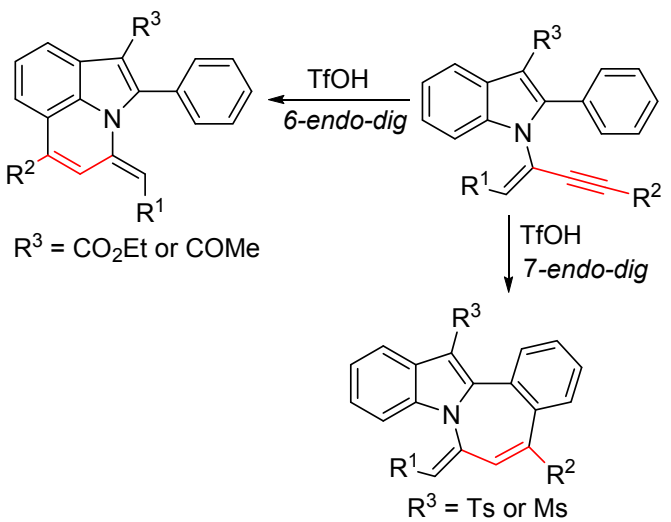

图式 15 吡咯并 $[3,2,1-\mathrm{ij}]$ 喹啉和苯并 $[3,4]$ 氮杂环庚烷 $[1,2-a]$ 吲 哚的选择性合成

Scheme 15 Selective synthesis of pyrrolo[3,2,1-ij]quinolines and benzo[3,4]azepino[1,2-a]indoles

\section{5 总结与展望}

综上所述, 基于无过渡金属催化下邻位基团参与的 炔烃环化反应近些年已取得很大进展, 为氮、氧、硫杂 环化合物以及多元并环结构化合物的合成提供了一条 绿色、原子经济型途径. 该类方法具有以下优点: (1)利 用亲电试剂等代替过渡金属的催化，节约成本; (2)底物 具有很高的原子经济型，并且反应操作简单，反应区域 选择性高; (3)构建了结构多样、价值有用的杂环化合物 骨架以及具有潜在价值的杂环化合物新骨架, 给天然产 物和药物的合成提供了新的选择. 然而, 该类发应尚具 有较大发展和应用空间：首先, 目前研究较多的是邻位 氮、氧、硫和苯基参与炔烃的环化, 还需发展新的邻位
基团参与炔烃的(多元)环化反应; 其次，很多药物分子 具有手性结构, 邻位基团参与的炔烃对映选择性环化报 道还较少; 此外, 多元并环结构的合成机理尚不明确, 值得进一步探究.

\section{References}

[1] (a) Boyarskiy, V. P.; Ryabukhin, D. S.; Bokach, N. A.; Vasilyev, A. V. Chem. Rev. 2016, 116, 5894

(b) Zheng, Z. T.; Wang, Z. X.; Wang, Y. L.; Zhang, L. M. Chem. Soc. Rev. 2016, 45, 4448

(c) Yuan, S. T.; Zhou, H. W.; Gao, L.; Liu, J. B.; Qiu, G. Y. S. Org Lett. 2018, 20, 562.

(d) Wang, Y. C.; Wang, R. X.; Qiu, G. Y. S.; Zhou, H. W.; Xie, W. L.; Liu, J. B. Org. Chem. Front. 2019, 6, 2471.

[2] (a) Huang, S. Y.; Li, X. X.; Lin, C. L.; Tang, W. P. Chem. Commun. 2012, 48, 2204.

(b) Chen, D. P.; Xing, G. D.; Zhou, H. W. Org. Chem. Front. 2015, $2,947$.

(c) Zhou, P.; Qiu, H. H.; Shi, J. C. Chin. J. Org. Chem. 2016, 36, 425 (in Chinese)

(周鹏，邱会华，施继成，有机化学， 2016, 36, 425.)

(d) Yu, J. J.; Yang, S.; Wu, Z.; Zhu, C. Chin. J. Org. Chem. 2019, 39,223 (in Chinese)

(余佳佳, 杨珊, 吴镇, 朱晨, 有机化学, 2019, 39, 223.)

(e) Mei, H. B.; Yin, Z. Z.; Liu, J.; Sun, H. L.; Han, J. L. Chin. J. Chem. 2019, 37, 292

[3] (a) Kirsch, S. F. Synthesis 2008, 3183.

(b) Jung, H. H.; Floreancig, P. E. J. Org. Chem. 2007, 72, 7359.

(c) Zhang, J.; Xiao, G. M. Petrochem. Technol. 2011, 40, 579 (in Chinese).

(张进，肖国民，石油化工, 2011, 40, 579.)

(d) Wang, Y.-C.; Wang, R.-X.; Qiu, G.; Zhou, H.; Xie, W.; Liu, J.-B. Org. Chem. Front. 2019, 6, 2471.

(e) Wang, Y. D.; Li, J. H.; Gao, Y.; Yang, Y.; Gao, Y.; Xu, Z. F. Hydrometallurgy 2020, 191, 105220.

(f) Wang, Y. C.; Liu, J. B.; Zhou, H. W.; Xie, W. L.; Rojsitthisak, P.; Qiu, G. Y. S. J. Org. Chem. 2020, 85, 1906.

[4] (a) Wang, Z.; Yang, L.; Liu, H. L.; Tan, Y. Z.; Bao, W. H.; Wang, M.; Tang, Z. W.; He, W. M. Chin. J. Org. Chem. 2018, 38, 2639 (in Chinese).

(王峥，杨柳，刘慧兰，谭英芝，包文虎，汪明，唐子龙，何卫民， 有机化学, 2018, 38, 2639.)

(b) Lu, L. H.; Wang, Z.; Xia, W.; Cheng, P.; Zhang, B.; Cao, Z.; He, W. M. Chin. Chem. Lett. 2019, 30, 1237.

(c) Cao, Z.; Zhu, Q.; Lin, Y. W.; He, W. M. Chin. Chem. Lett. 2019, 30, 2132.

(d) Wu, C.; Wang, Z.; Hu, Z.; Zeng, F.; Zhang, X. Y.; Cao, Z.; Tang, Z.; He, W. M. Org. Biomol. Chem. 2018, 16, 3177.

(e) Wu, C.; Xiao, H. J.; Wang, S. W.; Tang, Z. L.; Xia, W.; Li, W. F.; Cao, Z.; He, W. M. ACS Sustainable Chem. Eng. 2019, 7, 2169.

(f) Yuan, S.; Wang, Y.; Qiu, G.; Liu, J.-B. Chin. J. Org. Chem. 2017, 37, 566 (in Chinese).

(袁斯甜, 王艳华, 邱观音生, 刘晋彪, 有机化学, 2017, 37, 566.)

[5] (a) Wen, B.; Petersen, J. L.; Wang, K. K. Org. Lett. 2010, 13, 168.

(b) Zhu, H. T.; Ji, K. D.; Yang, F.; Wang, L. J.; Zhao, S. C.; Ali, S.; Liu, X. Y.; Liang, Y. M. Org. Lett. 2011, 13, 684.

(c) Yang, X. B.; Hu, F. Z.; Di, H. J.; Cheng, X. X.; Li, D.; Kan, X. L.; Zou, X. M.; Zhang, Q. C. Org. Biomol. Chem. 2014, 12, 8947.

(d) Luo, P. S.; Tang, R. Y.; Zhong, P.; Li, J. H. Chin. J. Org. Chem. 2009, 29, 1924 (in Chinese)

(罗培松, 汤日元, 钟平, 李金恒, 有机化学, 2009, 29, 1924.)

[6] Somei, M.; Yamada, F. Nat. Prod. Rep. 2005, 22, 73.

[7] Koradin, C.; Dohle, W.; Rodriguez, A. L.; Schmid, B.; Knochel, P. Tetrahedron 2003, 59, 1571

[8] Fiandanese, V.; Bottalico, D.; Marchese, G.; Punzi, A. Tetrahedron 
2008, 64, 7301.

[9] Stoll, A. H.; Knochel, P. Org. Lett. 2008, 10, 113.

[10] Arcadi, A.; Bianchi, G.; Inesi, A.; Marinelli, F.; Rossi, L. Eur. J. Org. Chem. 2008, 2008, 783.

[11] (a)Yue, D.; Larock, R. C. Org. Lett. 2004, 6, 1037. (b)Yue, D.; Yao, T.; Larock, R. C. J. Org. Chem. 2006, 71, 62.

[12] Voss, T.; Chen, C.; Kehr, G.; Nauha, E.; Erker, G.; Stephan, D. W. Chem.-Eur. J. 2010, 16, 3005.

[13] Meesin, J.; Pohmakotr, M.; Reutrakul, V.; Soorukram, D.; Leowanawat, P.; Kuhakarn, C. Org. Biomol. Chem. 2017, 15, 3662.

[14] Han, D. D.; Li, Z. M.; Fan, R. H. Org. Lett. 2014, 16, 6508.

[15] Shi, Q.; Li, P. H.; Zhang, Y.; Wang, L. Org. Chem. Front. 2017, 4, 1322.

[16] Chen, F.; Meng, Q.; Han, S. Q.; Han, B. Org. Lett. 2016, 18, 3330.

[17] Zhou, N. N.; Yan, Z. F.; Zhang, H. L.; Wu, Z. K.; Zhu, C. J. Org. Chem. 2016, 81, 12181.

[18] Huo, Z. B.; Gridnev, I. D.; Yamamoto, Y. J. Org. Chem. 2010, 75, 1266.

[19] (a) Fischer, D.; Tomeba, H.; Pahadi, N. K.; Patil, N. T.; Yamamoto, Y. Angew. Chem., Int. Ed. 2007, 46, 4764.

(b) Fischer, D.; Tomeba, H.; Pahadi, N. K.; Patil, N. T.; Huo, Z. B. Yamamoto, Y. J. Am. Chem. Soc. 2008, 130, 15720.

[20] Bianchi, G.; Chiarini, M.; Marinelli, F.; Rossi, L.; Arcadi, A. Adv. Synth. Catal. 2010, 352, 136.

[21] Kanazawa, C.; Terada, M. Chem.-Asian J. 2009, 4, 1668.

[22] Dev, K.; Maurya, R. RSC Adv. 2015, 5, 13102.

[23] Brahmchari, D.; Verma, A. K.; Mehta, S. J. Org. Chem. 2018, 83, 3339.

[24] Tan, J.; Tong, Y.; Chen, Z. Y. ChemistrySelect 2018, 3, 3886.

[25] Mancuso, R.; Mehta, S.; Gabriele, B.; Salerno, G.; Jenks, W. S.; Larock, R. C. J. Org. Chem. 2009, 75, 897.

[26] Du, J. Y.; Ma, Y. H.; Yuan, R. Q.; Nie, S. Z.; Ma, C. L.; Li, C. Z.; Zhao, C. Q. Org. Lett. 2018, $20,477$.

[27] Jung, Y.; Singh, D. K.; Kim, I. Beilstein. J. Org. Chem. 2016, 12, 2689.

[28] Warner, A. J.; Churn, A.; McGough, J. S.; Ingleson, M. J. Angew. Chem., Int. Ed. 2017, 56, 354.

[29] Verma, A. K.; Rustagi, V.; Aggarwal, T.; Singh, A. P. J. Org. Chem.
2010, 75, 7691 .

[30] Park, J. H.; Bhilare, S. V.; Youn, S. W. Org. Lett. 2011, 13, 2228.

[31] Uchiyama, M.; Ozawa, H.; Takuma, K.; Matsumoto, Y.; Yonehara, M.; Hiroya, K. Org. Lett. 2006, 8, 5517.

[32] Kanazawa, C.; Terada, M. Tetrahedron Lett. 2007, 48, 933.

[33] Mancuso, R.; Pomelli, C. C.; Malafronte, F.; Maner, A.; Marino, N.; Chiappe, C.; Gabriele, B. Org. Biomol. Chem. 2017, 15, 4831.

[34] (a) Zheng, Y. N.; Liu, M. L.; Qiu, G. Y. S.; Xie, W. L.; Wu, J. Tetrahedron $\mathbf{2 0 1 9}, 75,1663$

(b) Wang, Y. H.; Qiu, G. Y. S.; Zhou, H. W.; Xie, W. L.; Liu, J. B. Tetrahedron 2019, 75, 3850 .

[35] Schlemmer, C.; Andernach, L.; Schollmeyer, D.; Straub, B. F.; Opatz, T. J. Org. Chem. 2012, 77, 10118.

[36] Mehta, S.; Yao, T.; Larock, R. C. J. Org. Chem. 2012, 77, 10938.

[37] (a) Wang, R. X.; Yuan, S. T.; Liu, J. B.; Wu, J.; Qiu, G. Y. S. Org. Biomol. Chem. 2018, 16, 4501.

(b) Wang, Y. H.; Ouyang, B.; Qiu, G. Y. S.; Zhou, H. W.; Liu, J. B. Org. Biomol. Chem. 2019, 17, 4335.

[38] Mehta, S.; Waldo, J. P.; Larock, R. C. J. Org. Chem. 2008, 74, 1141.

[39] (a) Faizi, D. J.; Davis, A. J.; Meany, F. B.; Blum, S. A. Angew. Chem., Int. Ed. 2016, 55, 14286

(b)Issaian, A.; Faizi, D. J.; Bailey, J. O.; Mayer, P.; Berionni, G.; Singleton, D. A. Blum, S. A. J. Org. Chem. 2017, 82, 8165.

[40] Xu, J.; Yu, X. X.; Yan, J. X.; Song, Q. L. Org. Lett. 2017, 19, 6292.

[41] (a) Goldfinger, M. B.; Swager, T. M. J. Am. Chem. Soc. 1994, 116, 7895 .

(b) Goldfinger, M. B.; Crawford, K. B.; Swager, T. M. J. Am. Chem. Soc. 1997, 119, 4578.

[42] (a) Yao, T.; Campo, M. A.; Larock, R. C. Org. Lett. 2004, 6, 2677. (b) Yao, T.; Campo, M. A.; Larock, R. C. J. Org. Chem. 2005, 70, 3511.

[43] Li, C. W.; Wang, C. I.; Liao, H. Y.; Chaudhuri, R.; Liu, R. S. J. Org. Chem. 2007, 72, 9203.

[44] Chen, Y.; Huang, C. L.; Liu, X. C.; Perl, E.; Chen, Z. W.; Namgung, J.; Zhang, G.; Hersh, W. H. J. Org. Chem. 2014, 79, 3452.

[45] Alam, K.; Kim, J. G.; Kang, D. Y.; Park, J. K. Adv. Synth. Catal. 2019, 361, 1683.

$(\mathrm{Lu}, \mathrm{Y}$. 